\title{
Probability Concepts \\ In Geomorphology
}

GEOLOGICAL SURVEY PROFESSIONAL PAPER 500-G
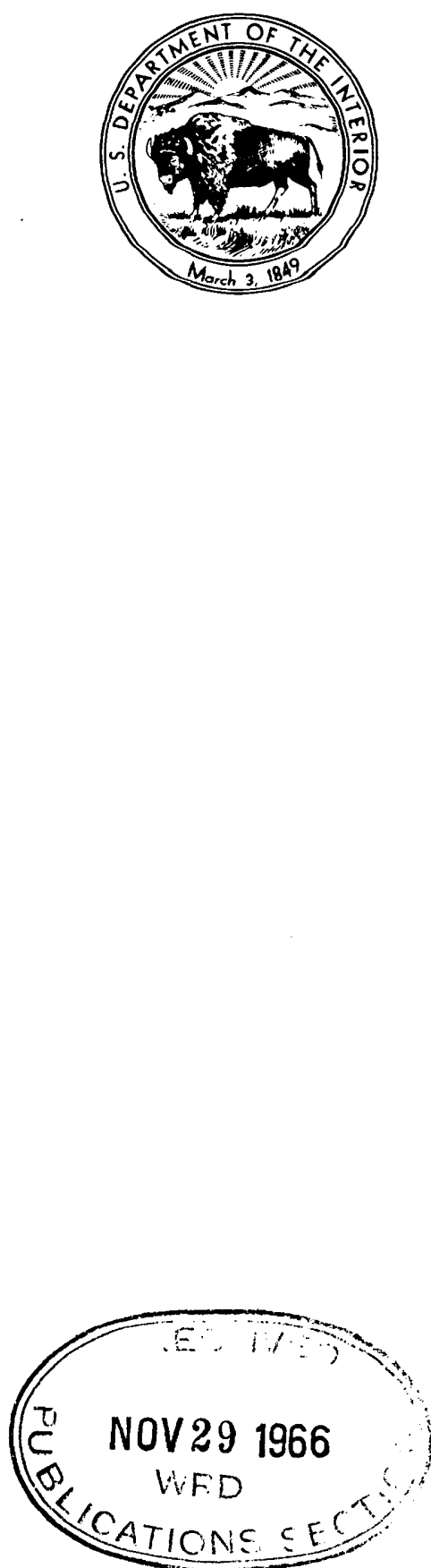


\section{Probability Concepts \\ In Geomorphology}

By A. E. SCHEIDEGGER and W. B. LANGBEIN

THEORETICAL PAPERS IN THE HYDROLOGIC AND GEOMORPHIC SCIENCES

GEOLOGICAL SURVEY PROFESIONAL PAPER 500-C

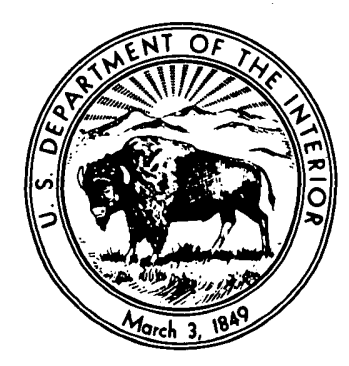

UNITED STATES GOVERNMENT PRINTING OFFICE, WASHINGTON : 1966 


\section{UNITED STATES DEPARTMENT OF THE INTERIOR \\ STEWART L. UDALL, Secretary \\ GEOLOGIGAL SURVEY \\ William T. Pecora, Director}

For sale by the Superintendent of Documents, U.S. Government Printing Office

Washington, D.C. 20402 - Price 20 cents (paper cover) 


\section{CONTENTS}

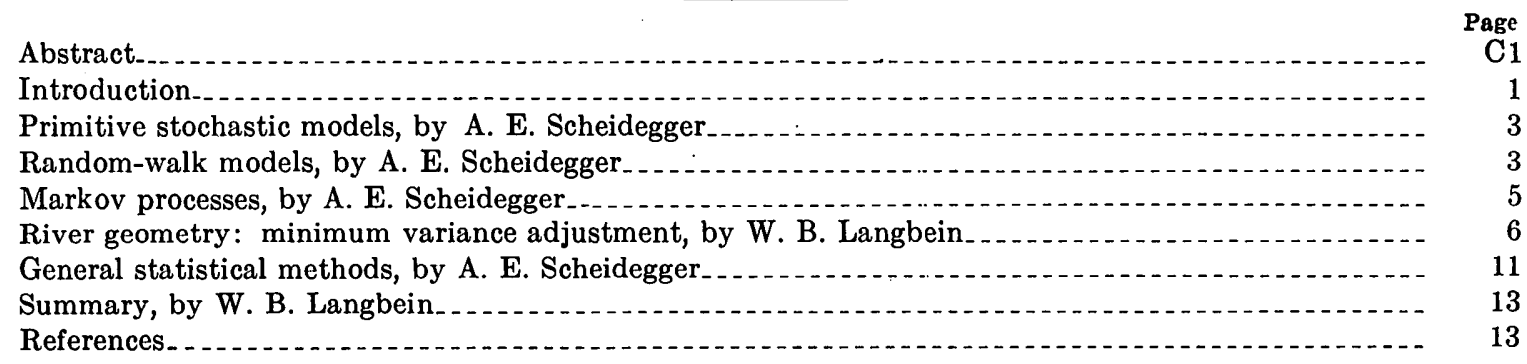

\section{ILLUSTRATIONS}

Figure 1. Lotka's pendulums-histogram showing the frequency distribution of the number of pendulums on one side of the central position

2-4. Graphs of slope development:

2. Basic slope development.

3. Error function, the slope profile resulting from a random walk

4. Decay of slope bank if autocorrelation is present..... 5

5. Diagram of a stream junction

6-10. Graphs:

6. Variation of velocity and depth of Rio Grande near Bernalillo, N. Mex . . . . . . . -

7. Relations of width, velocity, and depth to disoharge, Rio Galisteo at Domingo, N. Mex -..............

8. Sum of squares of hydraulic exponents for velocity, depth, width, shear, and friction

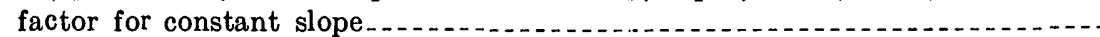

9. Total of $z^{2}+(m+z)^{2}+(m+f+z)^{2}+(1+z)^{2}+(1+m+z)^{2}$

10. Linear decay of a mountain range.

Page 


\title{
THEORETICAL PAPERS IN THE HYDROLOGIC AND GEOMORPHIC SCIENCES
}

\section{PROBABILITY GONCEPTS IN GEOMORPHOLOGY}

\author{
By A. E. Scheidegger and W. B. Langbein
}

\begin{abstract}
Rivers and landforms that are produced by the action of flowing water may be dominated by random processes. The complexity of the phenomena seems to be beyond complete resolution of the forces and resistances involved. An assumption of randomness appears to offer a direct approach to a study of landforms and of the hydraulic geometry of rivers.
\end{abstract}

\section{INTRODUCTION}

To understand the development of a landscape in terms of fundamental mechanical principles is a problem of extreme complexity. Landforms are numerous, and there are many aspects of otherwise similar landforms. The processes that are operative represent the cumulative effect of many small-scale events which are impossible to follow in detail. This is a condition that is not unusual in geomorphology and other natural sciences; it is so common that methods of statistical mechanics have been developed to cope with it. Bakhemeteff $(1941$, p. 99) argued for the use of statistical mechanics in hydraulics.

Throughout the development of geological science, many direct approaches at an explanation of landscape evolution have been tried. However, in view of the great complexity of the phenomena involved, these approaches may lead to as many explanations as there are cases, meaning that there is no general theory. A hypothesis based upon the concepts of statistical mechanics (that is, a probabilistic rather than a direct approach), therefore, may yield a satisfactory and practical theory.

One of the common assumptions that are introduced in statistical mechanics is the randomness of some of the processes. Under certain circumstances, this randomness can lead to logistic difficulties because in geomorphology nothing is really random; when it rains, the fall of each raindrop is governed by Newton's law of motion and by atmospheric friction. When the drop hits the ground and erodes some soil particles, again the appropriate laws of mechanics determine the initiation of events. The same is true for the formation and deepening of small gullies that form, say, on a slope and ultimately cause its decay. Yet, it would be quite hopeless to try to account for these processes in detail. As stated by Melton (1958), "The variability in any natural environment is the product of the happenings in many geologic periods ***. To argue that this variability could ever be entirely explained is absurd."

Our knowledge of the individual events can never be complete enough to deduce therefrom, say, the recession of a slope, the juncture of channels, or the velocity of the flow that caused them. Nevertheless, certain average relationships can be deduced from our incomplete knowledge of the individual processes, simply because the net effect of the many individual events is the same as if the individual events were to occur at random, although the events are, strictly speaking, entirely predetermined. This assumption of randomness, for example, has been used in the theory of flow of fluids through porous media (Scheidegger, 1964a). The flow channels (pores) are entirely rigid and given in any flow process, but their complexities are so great that the net effect of the superposition of individual flow effects is the same as if these flow effects were to occur at random. The random-walk generation of a drainage network (Leopold and Langbein, 1962), verified as realistic (Schenk, 1963), does not belie the fact that rivers join at specific places for specific reasons. But, the whole result is as if the process were random.

Each process is deterministic; however, the rates and periods differ, and the result may be indistinguishable from the random. Lotka (1925), for example, showed how a set of pendulums, each oscillating in a perfectly deterministic way, produced a net effect that is random in its characteristics. Lotka described a set of 26 pendulums having periods of $0.5,0.6 * * * 2.9,3.0$ seconds; these were set in motion simultaneously and then allowed to oscillate undisturbed. As the pendulums oscillated, the number that were on one side of the plumb position changed continuously about a mean value of 13 . A count was made of the number of 
pendulums on one side of the central or plumb position at the end of each tenth of a second (this being the difference in the periods) over a 25 -second period after the pendulums had been in motion for some time (250 observations). The resulting histogram shown in figure 1 conforms to a binomial distribution with a mean of 13 and a 0.5 probability that each of the 26 pendulums will be on one side of the plumb position. The theoretical standard deviation equals $\sqrt{26} \times 0.5 \times 0.5=2.55$, compared with 2.50 for the sample.

Among diverse landforms and among processes of land sculpture there are large numbers of examples that differ among themselves, not merely because of inhomogeneities of structure or of erosional resistance, but because readjustments to each action may not proceed at the same rates or time periods.

For an example of such readjustment consider the effect of a local depositional feature in a river channel. The chance emplacement of a bar, which slightly dams the stream, flattens the water-surface profile upstream from the obstruction and steepens the profile over the bar-that is, the velocity will slacken above the barrier with the net result that deposition is encouraged and less material reaches the bar. Over the bar itself the steepened profile increases velocity and tends to erode the obstruction. This increased erosion in the oversteepened reach and deposition in the flat area will, over a period of time, tend to eliminate the original bar and thus restore the channel to its earlier condition (Leopold and Langbein, 1962).

The reaction to the initial perturbation takes time, and therefore restorative adjustment may not be com-

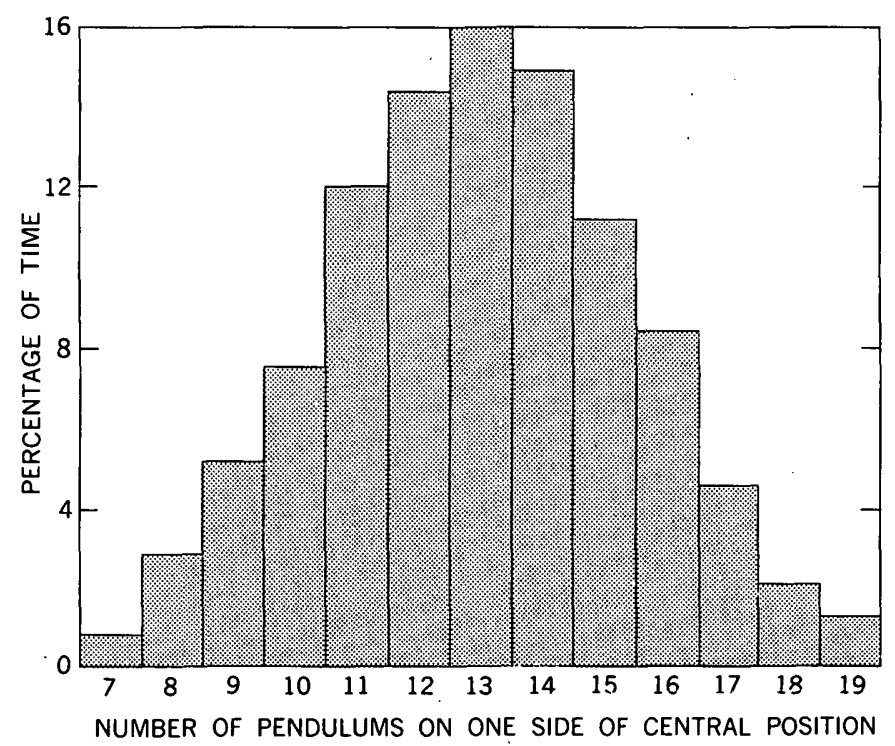

Figure 1.-Lotka's pendulums-histogram showing the frequency distribution of the number of pendulums on one side of the central position. plete before another chance event disrupts the adjustment, establishing a new series of events that inherits the characteristics of the old. If such readjustments are taking place, sporadically in time, not only at this one bar but at many, a variety of conditions will exist along the channel.

Many of these ideas are expressed in Hack's (1960) theory of dynamic equilibrium or in the steady-state theory of Chorley (1962). According to Hack, landforms can be explained on the basis of processes acting today through study of the relations between phenomena as they are distributed in space. This concept is close to the ergodic principle of statistical mechanicsthe replacement of time averages by space averages. The theory is independent of time and is concerned only with the relations between rocks and processes as they exist in space.

A homely example of Chorley's (1962) illustrates independence of the steady state of history. A stream of water flows into a bucket that has a hole in the bottom. The discharge through the hole is proportional to the depth of water. The level in the bucket reaches an equilibrium such that average inflow equals average outflow-this is a state of dynamic equilibrium. And then Chorley asks, was the bucket full or empty at the beginning?

The theory of dynamic equilibrium or the steadystate theory interpreted broadly stands in contrast to the formal stage-by-stage evolution of the landscape postulated by the Davisian geographic cycle. The dynamic equilibrium theory lends itself to quantitative analysis. The probability concepts outlined in this paper are of this school of thought. Both are uniformitarian in their approach.

The idea of using some type of statistical mechanics in geomorphology is, in principle, very old. When Davis (1924) spoke implicitly of the "average" geomorphic cycle, there was an element of probability implied in the use of the very word "average." Whenever statistics are used, one ought to specify the "population" in which the "average" is taken. A consistent way of introducing statistical mechanics in geomorphology was suggested by Leopold and Langbein (1962). The method of these authors was later analyzed with regard to its stiochastic basis by Scheidegger (1964b). Recently, Culling (1963) also introduced a statistical model which he based on the idea of a random-walk process.

In describing the steady state of rivers, a theorem of minimum variance adjustment among pertinent hydraulic factors is advanced. Its essence is that the increase in river discharge as it flows downstream is accommodated with minimum effect among the hydraulic factors, such as depth, width, and velocity. 
The principle appears in this light to be an extension of Le Chatelier's principle-a change in one element of a system in equilibrium is met by a reaction that tends to minimize the effect of the change.

Statistical mechanics may be adapted to the solution of geomorphic problems at three levels of sophistication. First, one can introduce primitive stochastic models in which semiempirical conjectures are made regarding the "average" behavior of a geomorphic system; second, one can postulate specific models, such as random-walk processes, and third, one can try to apply methods of ensemble theory (as originally in troduced by Gibbs into the statistical theory of gases) into geomorphology. These various possibilities will be discussed, one by one, below.

Since these theories are of a very general nature, and, in fact, represent more of a philosophy of treatment than a closed and final scheme, their potentialities will be illustrated by a few simple examples taken from earlier papers by us that are listed among the references.

\section{PRIMITIVE STOCHASTIC MODELS}

By A. E. Scheidegger

The simplest way in which statistical (or quasistatistical) considerations can be introduced into geomorphology is by trying to set up a theory for the "average" pattern of evolution of a landscape. This theory is essentially the scheme which, albeit unconsciously, has been traditionally applied to describe geomorphology when one was speaking of "standard" or "characteristic" cycles and slope evolution. This type of reasoning can also be put into mathematical terms by setting up a theoretical model for the "average" evolution of a geomorphic element, neglecting the detailed "microscopic" phenomena.

Scheidegger (1961a), Bakker and Strahler (1956), and Souchez (1963) have tried setting up a theoretical model for evolution of slopes. Thus, Scheidegger (1961a) reasoned that the denudation of a slope should proceed with a speed that is proportional to the declivity of this slope and that the denudation action would be normal to the slope. Denoting the height of a slopepoint in a cross section above some base line by $h$, the horizontal coordinate by $x$, and time by $t$, the above assumptions lead to the differential equation

$$
\frac{\partial h}{\partial t}=-\alpha \frac{\partial h}{\partial x} \sqrt{1+\left(\frac{\partial h}{\partial x}\right)^{2}}
$$

where $\alpha$ is some constant of proportionality:

This differential equation is nonlinear, and hence solutions must be obtained by numerical computation. The evolution of an originally straight slope bank is shown in figure 2. The denudation of slopes having varying lithology can easily be calculated (Scheidegger, 1964:c).

Although the general picture of the evolution of an average slope profile obtained in the present theory is not unreasonable, it would be desirable to specify more accurately the statistical concepts that are involved than can be done by the simple models that have been given.

\section{RANDOM-WALK MODELS}

By A. E. Scheidegger

The evolution of a landscape is primarily accomplished by a transport process: what is transported is simply the material that makes up the landscape. This material is in a relation to the height above base level of the points under consideration. The transport depends on the height above base level and involves a constant which depends on the density decrease that occur's where the ground is broken up.

Taking the grand view, it is obviously possible to regard the evolution of a landscape itself as a transport process: what is transported are the materials that constitute the heights above base level. The transport process has a stochastic element in it, that is, there is a random element determining which "particle" moves at what time so that the transport process can be regarded as the result of a "random walk" of the individual "particles" making up the landscape. As noted earlier, the process is not truly random, since the small-scale effects involved are all mechanically completely determined. However, the mechanics of these small-scale effects is so complicated that the details concerning most individual particles will remain forever unknown. Because of this, the process of landscape evolution can be treated as if it were random. As previcusly explained by Scheidegger (1964a), the following three types of specifications have to be made to

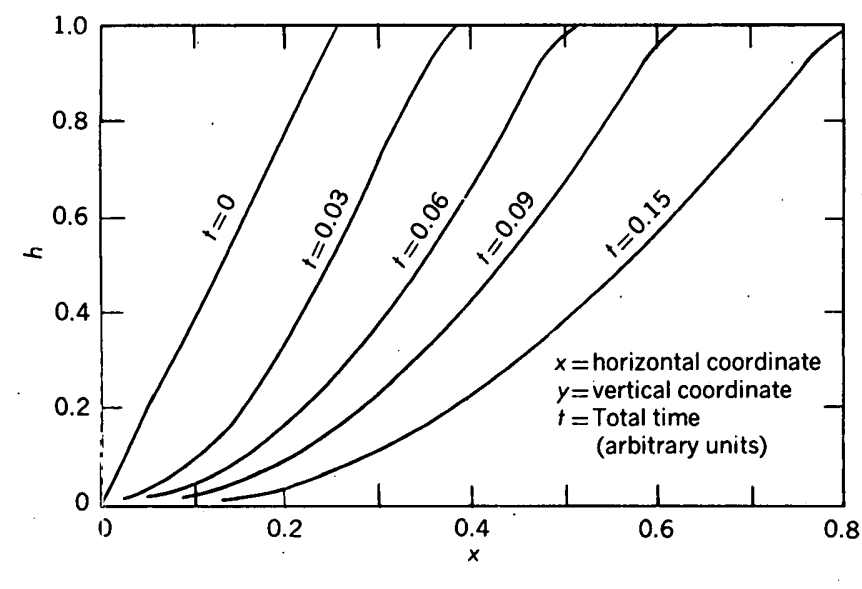

Figure 2.-Basic slope development. 
arrive at a valid transport model for such random-walk processes:

1. One must specify the ensemble. Such ensembles may consist of all systems that can be considered as identical to the sought-after relationships. To give some specific examples: if one considers a slope profile, then the ensemble includes all normal cross sections of a slope bank having certain properties, and the same would apply if one were to consider a mountain range; if one considers rivers having a given distribution of discharge, the ensemble includes all rivers having that distribution of discharge. It is for averages over such statistical ensembles that relationships are sought.

2. One must specify a priori the statistics within the ensemble. This includes questions as to whether the events are independent or correlated. The evolving patterns depend very much on the choice of statistics.

3. Finally, one must specify the microdynamic transport law.

Let us again illustrate the general theory of the evolution of a slope regarded as the result of a randomwalk process.

Case a. Assume that the phenomena occurring in the individual time steps are completely independent of each other. Several subcases can be distinguished.

Case $a$ I. - There are no microdynamic forces; that is, all changes are determined by stochastic processes. In a geomorphological context, this means that the "particles" on a slope are simply performing a random walk. Every "particle" on a slope has a certain chance to move forward; this chance is not dependent on conditions along the slope. Because of the central-limit theorem of probability theory (see, for example, Mises, 1931), the distribution function of the "particles" (and therewith of geomorphic height $h$ ) is subject to a diffusivity equation

$$
\frac{\partial h}{\partial t}=D \nabla^{2} h
$$

where $t$ is time, and $D$ is a diffusivity constant. The pattern of the decay of a slope profile corresponds to the solution of the diffusivity equation

$$
h=\frac{1}{2}-\frac{1}{2} \text { erf } \frac{-x}{\sqrt{4 D t}}
$$

where erf denotes the "error" function. This equation states that when the particles are subject to movement as described, they become distributed along the slope length, such that the height $h$, at any point $x$, takes the form of the "error" curve. The pattern is shown in figure 3 .

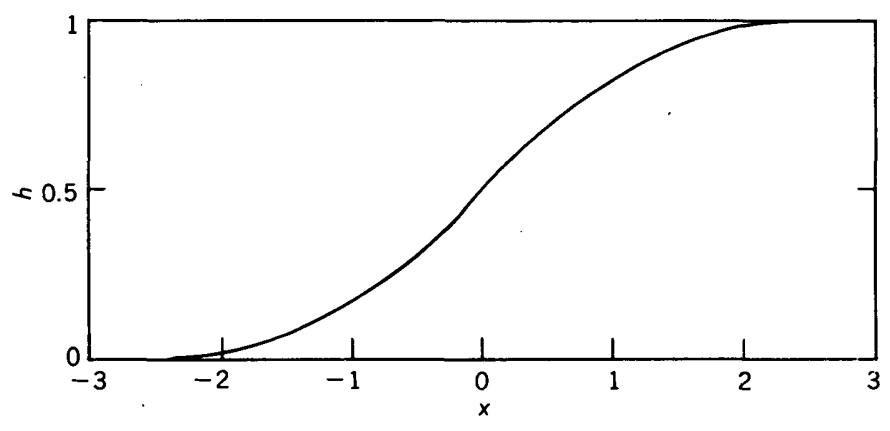

Figure 3.-Error function, the slope profile resulting from a random walk.

Case $a$ II.-Assume now that there are microdynamic forces, that is, forces in addition to those causing the random motion of the "particles." As previously explained in regard to the hydrodynamics of porous media (Scheidegger, 1964a), this introduces a mass-transport term in the diffusivity equation so that it reads

$$
\frac{\partial h}{\partial t}=D \nabla^{2} h-\mathbf{c} \nabla h
$$

where $\mathbf{c}$ is the average mass-transport velocity, that is, in a frame of reference moving with velocity c, one would again have the diffusivity equation. In fact, Culling (1963) has already investigated problems of this type where $h$, instead of denoting the height of a landscape, refers only to the thickness of an active layer (say, "soil") lying upon a slope; then any "accumulation" will gradually move downslope and spread out.

A possible generalization of the diffusivity equation can be arrived at if $D$ is no longer considered as a scalar, but as a tensor. Then, in customary tensor notation

$$
\frac{\partial h}{\partial t}=\nabla_{i} D_{i k} \nabla_{k} h-c_{i} \nabla_{i} h
$$

where the summation convention is assumed to be applied (see, for example, Jeffreys, 1932). Culling (1963) calculated several cases corresponding to the preceding two equations, which refer, as noted above, to the creep of a soil layer of thickness $h$ over a slope.

The present context concerns an interpretation of landscape height. Then, the mass-transport coefficient $c$, if not taken as zero as in case $a \mathrm{I}$, will presumably depend on the declivity of the slope. Since this coefficient describes the mean motion of "particles," one will presumably have to refer to the expression corresponding to that introduced earlier. There it was assumed that the vertical speed of lowering of a slope with declivity $\partial h / \partial x$ was given by

$$
v=\alpha \frac{\partial h}{\partial x} \sqrt{1+\left(\frac{\partial h}{\partial x}\right)^{2}}
$$


where $\alpha$ is some proportionality constant. Hence, the horizontal speed $c$ will be

$$
c=v /(\partial h / \partial x)=\alpha \sqrt{1+\left(\frac{\partial h}{\partial x}\right)^{2}}
$$

Thus, the differential equation (in one dimension) becomes

$$
\frac{\partial h}{\partial t}=D \frac{\partial^{2} h}{\partial x^{2}}-\alpha\left(\frac{\partial h}{\partial x}\right) \sqrt{1+\left(\frac{\partial h}{\partial x}\right)^{2}}
$$

which is nonlinear. It is, in fact, the same differential equation as in the section on primitive stochastic models, except that now a diffusivity term is added on its right-hand side.

Case b. Assume that there is autocorrelation between "particle motions" in succeeding time steps.

This case is again analogous to one occurring in the physics of flow through porous media (Scheidegger, 1958), where it has been shown that one now arrives at a "telegraph" equation (so called because it describes the electric behavior of a long telegraphic cable) rather than at a diffusivity equation. In one dimension this telegraph equation is

$$
\frac{\partial^{2} h}{\partial t^{2}}-\frac{D}{A} \frac{\partial^{2} h}{\partial x^{2}}+\frac{1}{A} \frac{\partial h}{\partial t}=0
$$

where $A$ and $D$ are two constants. The chief difference is the occurrence of the second time derivative which gives the equation some of the character of a wave equation. The solution of an originally vertical slope bank (at $t=0, H=1$ for $x>0$, zero otherwise; with $u=(D / A)^{1 / 2}$ is (Goldstein, 1951)

$$
\begin{aligned}
h(x, t) & =\frac{1}{2} e^{-t / 2 A}\left[I_{0}\left(\frac{\sqrt{u^{2} t^{2}-x^{2}}}{2 A u}\right)+2 \sum_{n=1}^{\infty}\left(\frac{u t-x}{u t+x}\right)^{n / 2}\right. \\
& \left.=0 \text { (otherwise). } \quad I_{n}\left(\frac{\sqrt{u^{2} t^{2}-x^{2}}}{2 A u}\right)\right] \text { for } 0<|x|<u t
\end{aligned}
$$

The situation is shown in figure 4 .

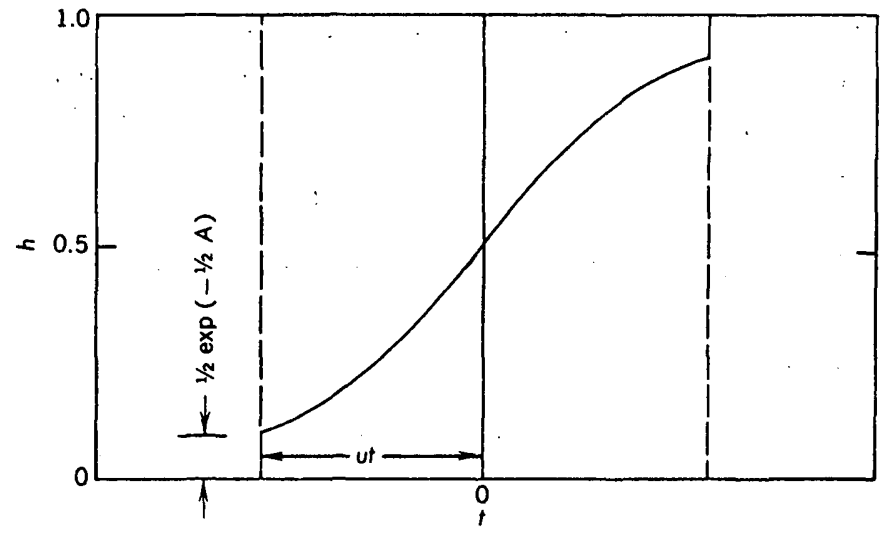

Figure 4.-Decay of slope bank if autocorrelation is present. 223-837 0-66-2

\section{MARKOV PROCESSES}

\section{By A. E. Scheidegaer}

The random-walk model without autocorrelation, discussed earlier, represents a special case of a rather general type of stochastic processes, namely, of Markov processes. Such processes are characterized by the property that the probability distribution of whatever stochastic variable is under consideration is completely determined for all $t>t_{0}$ by the value of the variable at $t_{0}$.

Let us consider the "average" profile of a slope bank. Its state, at a particular time $t$, is given by the probability distribution (not normalized) $h(x, t)$ of a continuous stochastic variable. We identify this distribution with the "average" profile of our slope bank ( $h$ denoting the height above a certain base level). We then assume that the evolution of the slope bank during the time interval $t, t+d t$ is determined solely by the state at time $t$. As noted, processes where this property obtains are called Markov processes.

One should again remark, of course, that there is nothing probabilistic about the actual development of the slope bank. The laws of mechanics determine what happens to each soil particle. However, we do. not know the exact configuration of a particular slope profile; we know only its probable configuration within a probable ensemble of slope profiles. This probable configuration, in spite of the determinism of the laws of mechanics, changes with time, and hence transition probabilities from one state to the next can be set up.

We have introduced $h(x)$ as a probability distribution which changes with time. This distribution, resulting from a Markov process which is continuous in space and time, can be described by the corresponding Fokker-Planck (sometimes also called Forward-Kolmogcrov) equation, which has the form of a general diffusivity equation (see Bharucha-Reid, 1960)

$$
\frac{\partial h(t, x)}{\partial t}=\frac{1}{2} \frac{\partial^{2}\left[a^{\prime}(t, x) \cdot h(t, x)\right]}{\partial x^{2}}-\frac{\partial\left[b^{\prime}(t, x) \cdot h(t, x)\right]}{\partial x} .
$$

Here, $a^{\prime}$ and $b^{\prime}$ are "coefficients" equal to the time derivative of the variance and mean of the stochastic variable.

The mere assumption of the evolution of the state of a landscape corresponding to a Markov process, therefore, entails a description of this evolution by means of a diffusivity-type (Fokker-Planck) differential equation. The specification of the coefficients $a$ and $b$ allows one enough latitude to describe a variety of cases. A particular choice for $a$ and $b$ leads to the random-walk theory explained in the preceding paper; however, there is the prospect that full generality of the cases that can be adduced is not yet clear. 


\section{RIVER GEOMETRY: MINIMUM VARIANCE} ADJUSTMENT

By W. B. LANGBEIN

Consider a simple network, as shown in figure 5, of the channels in a homogeneous noncoherent alluvium. The problem concerns how the channels represented accommodate the given discharges. The increased discharge below the junction might be taken up in increased width, depth, or velocity, or any combination with corresponding variations in slope, shear, and friction. The problem is examined on an assumption that the increased discharge is accommodated with least variance in these several properties.

Use is made of the Leopold-Maddock (1953) model of the hydraulic geometry of rivers in which the dependent variables among the several river properties vary in terms of discharge, $Q$, as the independent variable

$$
\begin{aligned}
& \text { velocity } \sim Q^{m}, \\
& \text { depth } \sim Q^{\prime}, \\
& \text { width } \sim Q^{b},
\end{aligned}
$$

since $\log v=$ constant $+m \log Q$, etc.;

$$
\begin{aligned}
& m=\sigma_{\log v} / \sigma_{\log Q}, \\
& f=\sigma_{\log D} / \sigma_{\log Q}, \\
& b=\sigma_{\log w} / \sigma_{\log Q} .
\end{aligned}
$$

Thus, the hydraulic exponents of the dependent variables equal the ratios of the standard deviation of the logarithms of a dependent variable to the standard deviation of the logarithms of the independent variables. The squares of these ratios are called variance.

The model in this treatment is linear with regard to the hydraulic exponents or the logarithmic standard deviations. Thus, those standard deviations are related to each other by simple linear equations. For example,

$$
v \times D \times w=Q \text {. }
$$

which, according to the Leopold-Maddock model becomes

or

$$
Q^{m} \cdot Q^{s} \cdot Q^{b} \sim Q^{1}
$$

$$
m+f+b=1 \text {. }
$$

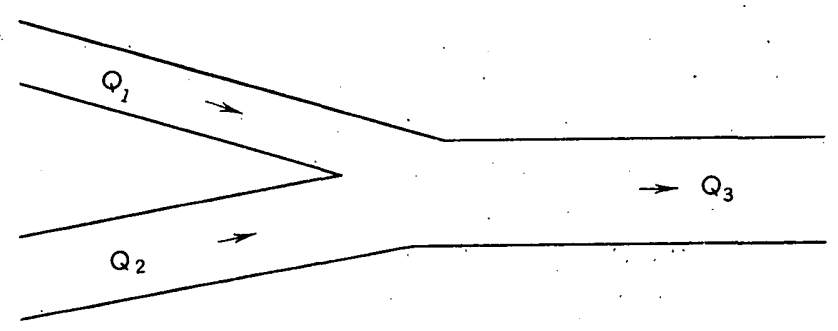

Figure 5.-Stream junction.
This follows from the relationship involving the hydraulic indices which are exponents. However, the same results are obtained from the statistical statements.

Given

therefore

$$
Q=v \times D \times w
$$

and

$$
\log Q=\log v+\log D+\log w
$$

$\sigma_{\log Q}^{2}=\sigma_{\log v}^{2}+\sigma_{\log D}^{2}+\sigma_{\log w}^{2}+2 r \sigma_{\log v} \sigma_{\log D}$

$$
+2 r \sigma_{\log D} \sigma_{\log w}+2 r \sigma_{\log v} \sigma_{\log w} \text {. }
$$

If, as in the model, the several coefficients of correlation, $r$, are each equal to unity, then,

and

$$
\sigma_{\log Q}^{2}=\left(\sigma_{\log D}+\sigma_{\log D}+\sigma_{\log w}\right)^{2}
$$

$$
\begin{array}{r}
\sigma_{\log Q}=\sigma_{\log v}+\sigma_{\log D}+\sigma_{\log w} \\
1=\frac{\sigma_{\log \vartheta}}{\sigma_{\log Q}}+\frac{\sigma_{\log D}}{\sigma_{\log Q}}+\frac{\sigma_{\log w}}{\sigma_{\log Q}}
\end{array}
$$

or

and

$$
1=m+f+b, \text { as before, }
$$

$$
m=\sigma_{\log v} / \sigma_{\log Q} ; f=\sigma_{\log D} / \sigma_{\log Q} ; b=\sigma_{\log w} / \sigma_{\log Q} .
$$

With actual data and a finite standard error, the coefficient of correlation can be as close to unity as desired by extending the range of the data.

A river is described by its several hydraulic properties, which are presumed to be distributed at random. Let each property be represented by a standardized variate $\left(x^{\prime}-\bar{x}^{\prime}\right) / \epsilon$, where $x^{\prime}$ is the logarithm of a given property (such as velocity, depth, and width); $\bar{x}^{\prime}$ is the logarithmic mean of the property at $N$ points of observation, each associated with a value of the independent variable; and $\epsilon$ is the standard deviation of the logarithms of the hydraulic properties. Similar standardized variates exist for $x^{\prime \prime}, x^{\prime \prime \prime}$, etc. Moreover, the standardized variates of the several properties are initially assumed to have the same value of $\epsilon$ and to constitute a homogeneous population. If all properties are independent, then the most probable combination is that where

$$
\sum_{1}^{N}\left[\left(x^{\prime}-\bar{x}^{1}\right) / \epsilon\right]^{2}+\sum_{1}^{N}\left[\left(x^{\prime \prime}-\bar{x}^{\prime \prime}\right) / \epsilon\right]^{2}+\text { etc }=\mathrm{a} \text { minimum. }
$$

Letting

$$
\begin{aligned}
& \sum_{1}^{N}\left[\left(x^{\prime}-\bar{x}^{\prime}\right) / \epsilon\right]^{2}=N \sigma_{1}^{2}, \\
& \sum_{1}^{N}\left[\left(x^{\prime \prime}-\bar{x}^{\prime \prime}\right) / \epsilon\right]^{2}=N \sigma_{2}^{2}, \text { etc. }
\end{aligned}
$$


where $N$ is equal to the number of points whëre observations are made of $x^{\prime}, x^{\prime \prime}$; etc., and $\epsilon$ is a factor common to all variables. The above statement is equivalent to the statement that

$$
\sigma_{1}^{2}+\sigma_{2}^{2}+\sigma_{3}^{2}=a \text { minimum. }
$$

If the $\sigma$ 's are each divided by standard deviation of the sum $\left(x^{\prime}+x^{\prime \prime}+\right.$ etc.) at the points of observation (all in logarithms), then the ratios correspond to the hydraulic exponents.

The independence among values of the hydraulic properties, referred to in the above equation, does not preclude constraints that specify relationships among the several factors. An illustration will show what is meant by constraints.

Assume that each river of a large ensemble of many identical rivers is characterized by several distinguishable factors, $F_{1}, F_{2}, F_{3}$, etc. These values have a mean and a standard deviation among the rivers which may be modeled by tossing a large number, $N$, of fair devices (such as coins, dice) each with $F$ distinguishable faces. Each toss of the $N$ devices represents a river. The relative frequency, $k_{1}, k_{2}$, etc., among $N$ devices represents the values of $F_{1}, F_{2}$ for that toss or, as it were, for that "river." The question concerns their most probable values. It is asserted here without proof that the most probable frequenciés occur when

$$
\left(k_{1} / N\right)^{2}+\left(k_{2} / N\right)^{2}, \text { etc. }=\mathrm{a} \text { minimum, }
$$

where $k_{1}, k_{2}$, etc., is the frequency of each distinguishable factor and where $k_{1}+k_{2}$, etc. $=N$. This statement, without constraint, is obviously satisfied when $k_{1}=k_{2}$, etc.

To illustrate the effect of a constraint let us now consider only those tosses in which $k_{2}=2 k_{1}$. This means that even though all tosses and all devices remain independent of the others, only those tosses of the $N$ devices in which $k_{2}=2 k_{1}$ qualify. What are now the most probable values for $k_{1}, k_{2}, k_{3}$, etc.? Introducing this constraint in the sum of squares

$$
\left(k_{1} / N\right)^{2}+\left(2 k_{1} / N\right)^{2}+\left(k_{3} / N\right)^{2}+\ldots \text { a minimum. }
$$

The general case has not been worked out but consider the case where there are three factors, $F_{1}, F_{2}$, and $F_{3}$. Then

$$
\left(k_{1} / N\right)^{2}+\left(2 k_{1} / N\right)^{2}+\left(1-3 k_{1} / N\right)^{2}=\text { a minimum, }
$$

or

$$
\begin{aligned}
& k_{1} / N=0.215, \\
& k_{2} / N=0.43, \\
& k_{3} / N=0.355 .
\end{aligned}
$$

These values can be verified for large values of $N$ by the ordinary statistics of combinations. The product $p\left(k_{1}\right) \cdot p\left(2 k_{1}\right) \cdot p\left(N-3 k_{1}\right)$ is a maximum when $C_{k_{1}}^{N} \cdot C_{2 k_{1}}^{N}$ . $C_{N-3 k_{1}}^{N}$ is a maximum. This product is a maximum when $k_{1}=0.215 N$ for large values of $N$.

Although in the model the factors $F_{1}, F_{2}$, etc., are drawn from a population having identical standard deviations, by stating a constraint $k_{2}=2 k_{1}$, the standard deviations of the factors $F_{1}, F_{2}$, etc., as well as their most probable values, become distinctive. Note, too, the sum of squares gives the most probable values without need to develop the separate frequency distributions.

One may also observe that the introduction of constraints increases the sum of squares. The fewer the constraints, that is, the more relaxed, the lower the sum of squares. For example, the sum of squares without constraint is 0.33 ; the introduction of the constraint $k_{2}=2 k_{1}$ increases the sum of squares to 0.36 . Effects of constraints and relaxations on hydraulic examples will also be shown.

The statement that the sum of squares of the variables is a minimum is very close to the principle of total least work in the relaxation adjustment of linear networks, such as structural frames. Southwell (1940, sec. 98) stated, "In a framework we have to determine that distribution of joint displacements which, subject to the overriding condition of continuity, entails a minimum value of the total energy - this being (by Hooke's law) a quadratic function of the displacements." In a network of pipes, least work occurs when the product discharge $(Q)$ by head loss $(H)$ is a minimum, that is, when

$$
\Sigma Q H=\text { a minimum. }
$$

In a linear network $H=a Q$, where $a$ is a constant of proportionality of head loss to discharge; therefore,

and

$$
\Sigma a Q^{2} \text { is a minimum }
$$

$$
\Sigma H^{2} / a \text { is a minimum. }
$$

If the diversity among the several branches is not extreine, then with little loss of accuracy one may use average values; thus,

$$
\bar{a} \Sigma Q^{2}+\overline{1 / a} \Sigma H^{2} \text { is a minimum. }
$$

In a set of trial solutions for a given network, it will be found that one quantity increases as the other decreases. Thus, decreasing variability in one quantity is purchased at the expense of increasing variability of the other. The relaxed solution occurs when the sum of squares is least. 
Le Chatelier's principle as defined in the American Geological Institute Glossary (1957, p. 166) can lead directly and simply to a statement of minimum variance adjustment. For example, consider an increase in discharge in a flume in which flow had produced a stable regimen. Or, consider the addition of flow at a junction with a stream that has a stable regimen above the junction. The increase produces changes in velocity, depth, width, shear, and possibly other things. Since the regimen is stable, according to the Le Chatelier principle, each of these changes produces effects in the others that react against the change. The effect is the same as stating that each factor resists change, or in other words, the variance of each tends toward zero. Since all of them cannot be zero, it appears that the adjustment is such that the total variance is minimal.

The concept of the probability of a state of nature raises philosophical difficulties that are at present controversial. One difficulty is that the concept is not operational. It does not give rules for deciding which data are relevant and therefore to be included in the "state of nature."

Such knowledge must come from the mechanics of the processes. Hydraulic geometry is described by such properties as width, depth, hydraulic radius, velocity, shearing force, friction factor, sediment transport, intensity of power expenditure, and possibly others. There is therefore a complex mix of properties that might be involved in a minimum variance adjustment. However, not all have equal weight. Their relative weights could be resolved by data. However, initial inquiry indicates that a large set of problems can be explained by giving the dominant factors; width, hydraulic radius, velocity, shear, and friction factors a weight of unity, and the others a weight of zero. The matter is simplified if the channels are sufficiently wide that mean depth equals the hydraulic radius.

Five cases are considered, as successive factors are relaxed or constrained, and these cases are compared with laboratory and field data.

Case 1. If width and slope are constrained, then all the increase in discharge below the junction must be accommodated in depth and velocity and accompanying changes in shear and friction

Since discharge is the independent variable, it may be assigned a variance of unity. Width and slope have zero variance. If the variance of depth is represented by $\mathrm{f}^{2}$, then those of all dependent variances are

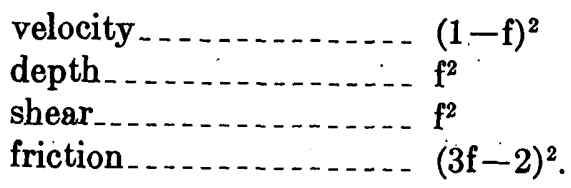

The variance of velocity follows because velocity equals discharge divided by depth and width, and width is constant. Shear equals the product of unit weight of water, depth, and slope. Since unit weight and slope are constant, shear varies only with the mean depth. Friction (the Darcy-Weisbach friction factor) with slope constant is proportional to the mean depth divided by the square of the velocity. It is assumed that the mean depth equals the hydraulic radius.

If the change in discharge is accommodated equally as between changes in depth and velocity, then $f=0.50$. If, in addition, the variances in shear and friction are also minimized, then $f=0.58$. Actual data give results within this range. These results indicate that when width and slope are constant, then 50-58 percent of a change in discharge is accommodated by change in depth, and the remainder by change in velocity.

The sum of squares of the dependent variables is 0.94 , computed as follows:

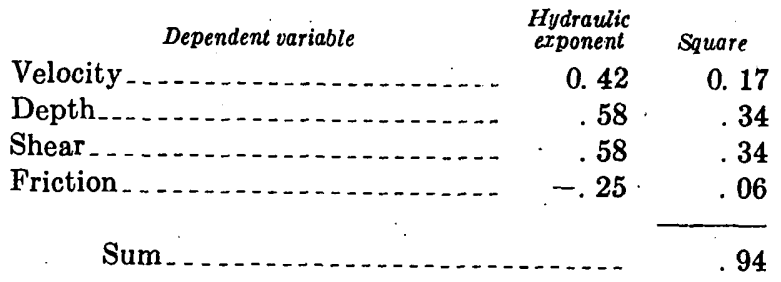

A multiple regression of the 42 runs for which bedforming processes were active in a set of constant-width flume experiments reported by Simons, Richardson, and Albertson (1961) indicated that depth varied as the 0.52 power of the discharge for constant slope. On the Rio Grande at Bernalillo, N. Mex., where the riverbed is sand and width and slope are constant over a wide range of discharges, depth varies as the 0.55 power of the discharge. (See fig. 6.)

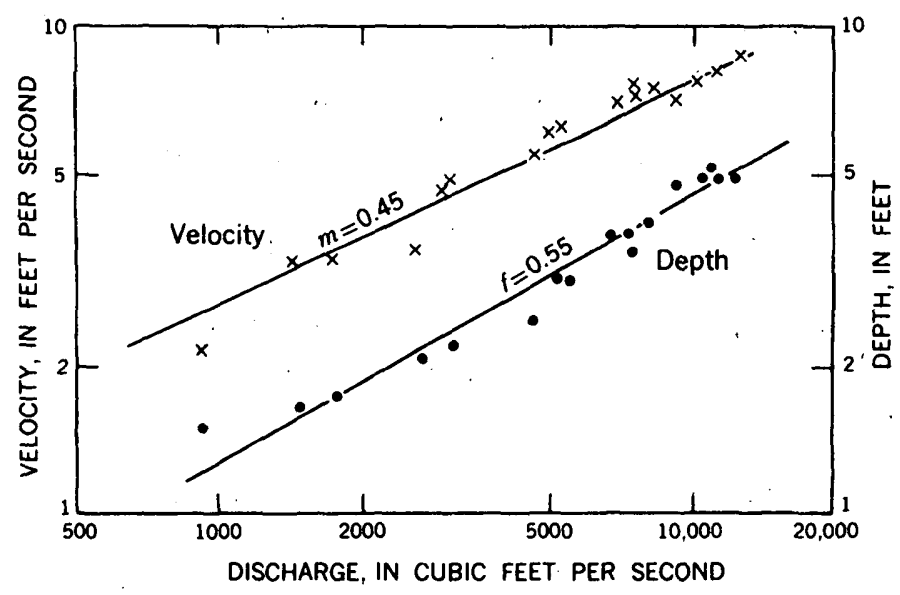

Figure 6.-Variation of velocity and depth of Rio Grande near Bernalillo, N. Mex., 1948; width between 270 and 280 feet. 
Case 2. Width is relaxed and becomes a dependent variable; slope is still constant. Again taking discharge as the independent variable, it may be assigned a variance of unity. If the variances of the dependent variables, velocity and depth, are represented by

$$
\begin{aligned}
& \text { velocity . . ................... } m^{2} \\
& \text { depth.................... } f^{2} \text {, }
\end{aligned}
$$

then those of the remaining dependent variables are

$$
\begin{aligned}
& \text { width ............. }(1-m-f)^{2} \\
& \text { bed shear............. } f^{2} \\
& \text { friction ............ }(f-2 m)^{2} \text {. }
\end{aligned}
$$

Summing these five terms, one finds that a minimum is reached when $m=5 / 23$ and $f=7 / 23$. These results signify that 22 percent of a change in discharge would be accommodated by a change in velocity, 30 percent by a change in depth, and consequently, the remaining 48 percent by a change in width. The sum of squares is now reduced to 0.478 .

Figure 7 shows the way in which the Rio Galisteo at Domingo, N. Mex., accommodates changes in discharge. The river at this gaging station is at virtually constant slope, and the bed and banks are of medium sand. The slopes of the graphs shown correspond to values of $m=0.24$ and $f=0.27$. Results obtained for stream channels in noncoherent materials that are reformed with each change in discharge as, for example, the continuously reforming channels below Emmons Glacier, vividly described by Fahnestock (1963) gave values of $m=0.27$ and $f=0.33$. However, these results apply to different channels having different slopes. Graphical analysis of a set of flume experiments with channels developed in noncohesive 0.67 millimeter sand by Wol-

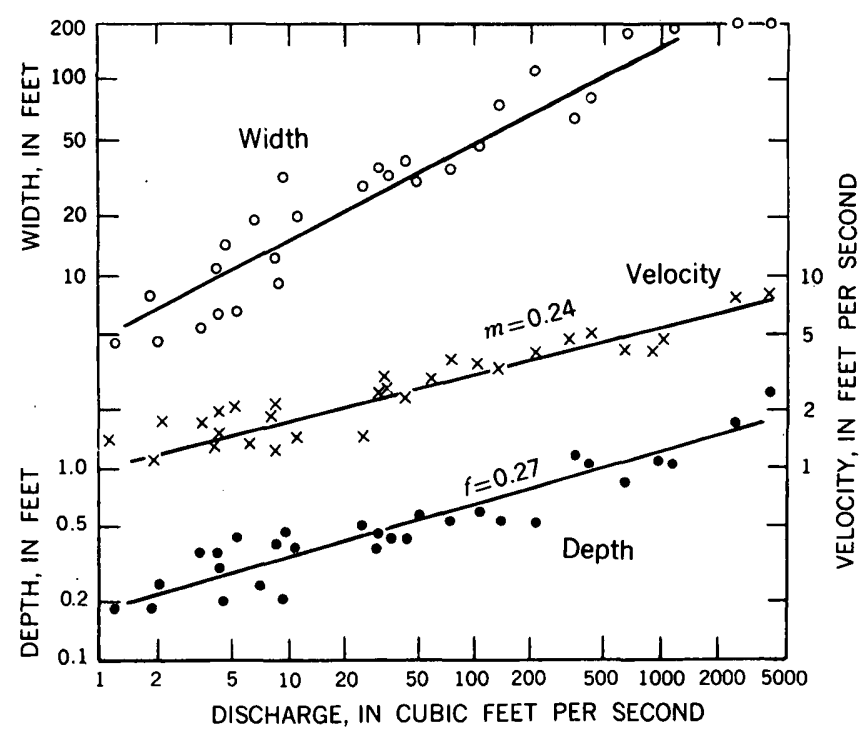

Figure 7.-Relations of width, velocity, and depth to discharge, Rio Galisteo at Domingo, N. Mex., 1957-58. man and Brush (1961) gave values of $m=0.22$ and $f=0.29$, at constant slope.

Four "at-a-station" cases (slope constant) are considered. The sum of squares is shown by the family of curves on figure 8 . In case 1 width, as noted, is fixed. This solution lies along the line $b=0$. In case 2 width, as noted, is free to adjust to each flow, and there is no constraint. The solution occupies the "eye" of the family of curves. In case 3 , which has not yet been discussed, there is the constraint that depth varies as the square of the velocity. The solution lies at a point of tangency to the line $f=2 \mathrm{~m}$.

Case 2A.-This case is shown in figure 8 and describes the usual "at-a-station" case on a river in a humid region. The channel is developed at a bankfull or channel-forming discharge, and the banks are sufficiently cohesive that the channel is not reformed at lower flows. This relation of channel to discharge is described by the constraint $b=0.55 f$, where the value of 0.55 is the slope of the graph between mean depth and width on logarithmic chart as given by the sine cross section cited by Nizery and Braudeau (1955).

Case 2B.-It is of interest to relax $m^{2}+f^{2}+b^{2}$ $+(f+-z)^{2}+(f+z-2 m)^{2}$, these terms again representing velocity, depth, width, shear, and the friction factor, without constraint, giving $m=1 / 7 ; f=3 / 7$; and $z=$ $-2 / 7$, where $z$ is the hydraulic exponent for slope. The sum of squares is 0.428 , lowest for cases $1-3$. This case and the figures obtained correspond with the flume experiments reported by Ackers (1964), who obtained the hydraulic gradients: $m=0.15 ; f=0.42$;

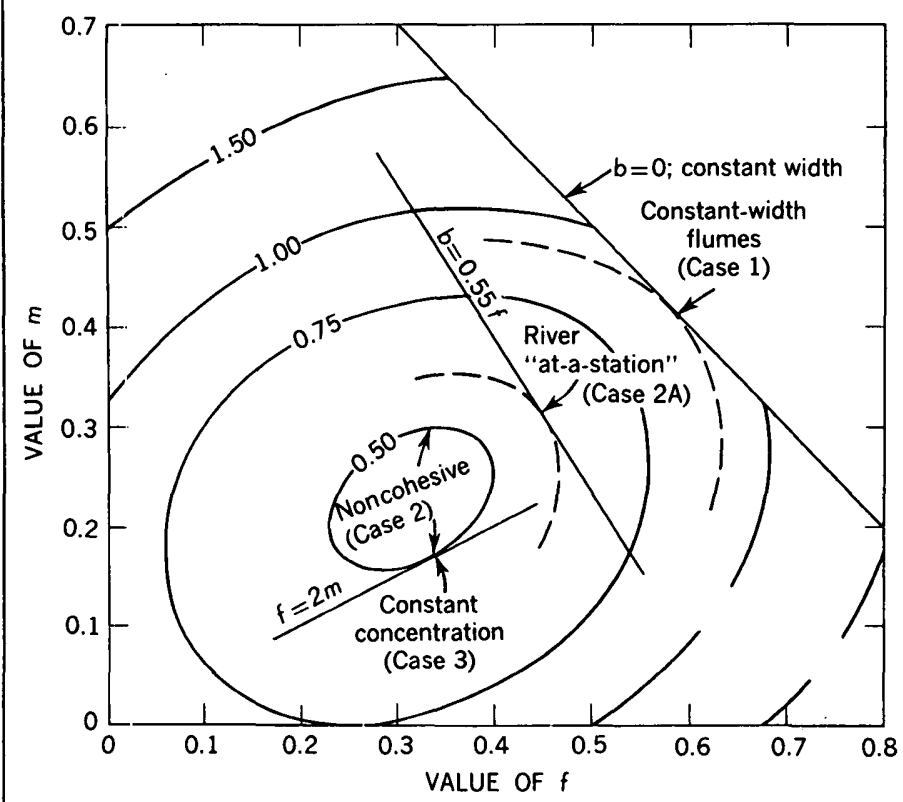

FIGURE 8.--Sum of squares of hydraulic exponents for velocity, depth, width, shear, and friction factor for constant slope. 
$b=0.43 ;$ and $z$ uncertain. Because in these experiments there is no continuity of sediment, this case is not to be confused with a canal network, case 4, that will be discussed.

Case 3. It is specified that sediment transport varies in proportion to the rate of discharge and that slope is constant. Load per unit width is proportional to mean velocity cubed for mixtures of sediment of different sizes (Thomas Maddock, Jr., written commun., 1965). Then, because load per unit volume is constant, depth must vary as the square of the velocity. In this case, the respective variances are

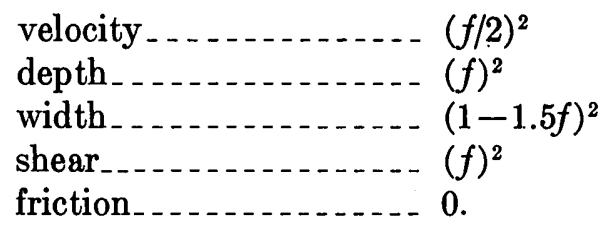

Summing these terms, one finds that a minimum is reached when $f=1 / 3$ and therefore $m=1 / 6$ and $b=1 / 2$. Because of the addition of a constraint, the sum of squares is increased to 0.50 . There are no flume experiments that apply to this case.

Case 4 (straight canals). If slope is relaxed, or in other terms, slope also is a dependent variable, and there is continuity of sediment as well as of water, then a longitudinal profile is developed and a system of canals is approximated. In this case, the profile can develop so that the variation in shear and friction is equally divided, for the above sum of squares is a minimum only when this is true. The variance of shear is $(f+z)^{2}$ and that of friction $(f+z-2 m)^{2}=z^{2}$. Since uniform charge requires that $m=0.5 f$, these two variances are equal when $z=-m$. However, the profile developed also is free to adjust so that the several aspects of stream power are as equably accommodated as is possible. Various aspects of stream power and their variances are

\begin{tabular}{|c|c|c|}
\hline Power per unit & & Variance \\
\hline Length per unit discharge & $\frac{Q \Delta H}{Q \Delta L} \sim s$ & $z^{2}$ \\
\hline Volume..... & $\frac{Q \Delta H}{D w \Delta L} \sim v s$ & $(m+z)^{2}$ \\
\hline Bed area......... & $\frac{Q \Delta H}{w \Delta L} \sim v D s$ & $(m+f+z)^{2}$ \\
\hline Length_... & $\frac{Q \Delta H}{\Delta L} \sim Q s$ & $(1+z)^{2}$ \\
\hline Time of stream travel(Rubey, 1938). & $\frac{Q \Delta H}{\Delta t} \sim Q v s$ & $(1+m+z)^{2}$. \\
\hline
\end{tabular}

The total variability is therefore the sum of the squares

$$
z^{2}+(m+z)^{2}+(m+f+z)^{2}+(1+z)^{2}+(1+m+z)^{2} .
$$

Since $m=0.5 f$ and $z=m$, this sum of squares is a minimum when $z=-1 / 6$, and $m=1 / 6, f=0.33$, and $b=0.50$. These values correspond with those that have long ago been derived empirically (Lacey, 1930) for "regime" canals in homogeneous noncoherent materials. This analysis contains as implicit or explicit conditions, steady discharges in each reach, uniform sediment concentration along the channel, and active sediment movement in the range satisfied by Maddock's statement of transport.

The theoretical basis of regime equations for stable channels rests, it is suggested, not so much on considerations of dynamics as on statistical mechanics.

Case 5 (rivers, downstream). Rivers have additional liberties and are even further relaxed than canals. Rivers, for example, have no lateral constraint and are free to meander. For the river case there are no constraints save the condition regarding sediment concentration or charge. In rivers, as is well known, sediment concentration decreases downstreamward because of flatter land gradients. Although this reduction in sediment concentration has been in the past associated with discharge (Brune, 1948), slope seems a better parameter because it is more directly related to the factor directly responsible. An analysis of existing data shows that concentration varies about as the 0.25 power of the slope. Since, as before, load per unit width varies as the velocity cubed, the condition that would apply to rivers is $m=1 / 2 f+0.12 z$.

The total sum of squares is then a minimum when $m=0.12+$ and $z=-0.55$. Using these figures, it follows from $m=0.5 f+0.12 z$ and $m+f+b=1.0$ that $f=0.38$ - and $b=0.50$, results that have close resemblance to nature (Leopold and Maddock, 1953).

If concentration remains constant (that is, $m=1 / 2 f$ ), then the sum of squares, without other constraint, is a minimum when $z=-0.56, m=1 / 6, f=1 / 3$, and $b=0.50$. The $m, f$, and $b$ values are the same as the canal case, whereas the hydraulic exponent for slope is the same as the river case. Evidently the slight downstream decrease in concentration does not affect either the profile or width. The decrease in concentration is accommodated entirely by changes in velocity and depth.

These relationships are clearer on figure 9 , which shows a family of curves defining the sum of squares $z^{2}+(m+z)^{2}+(m+f+z)^{2}+(1+z)^{2}+(1+m+z)^{2}$ in terms of $m$ and $z$. The diagram shows the curves for the condition that $m=1 / 2 f$ (constant concentration) and that $m=1 / 2 f+0.12 z$ (downsiream decrease in concentration). The two sets of curves differ only for large values of ' $z$. This diagram may help to show how the "profile" cases are related to each other:

1. The canal case is subject to the constraint as derived above for case 4 that variance in shear and friction are equally divided, and so 


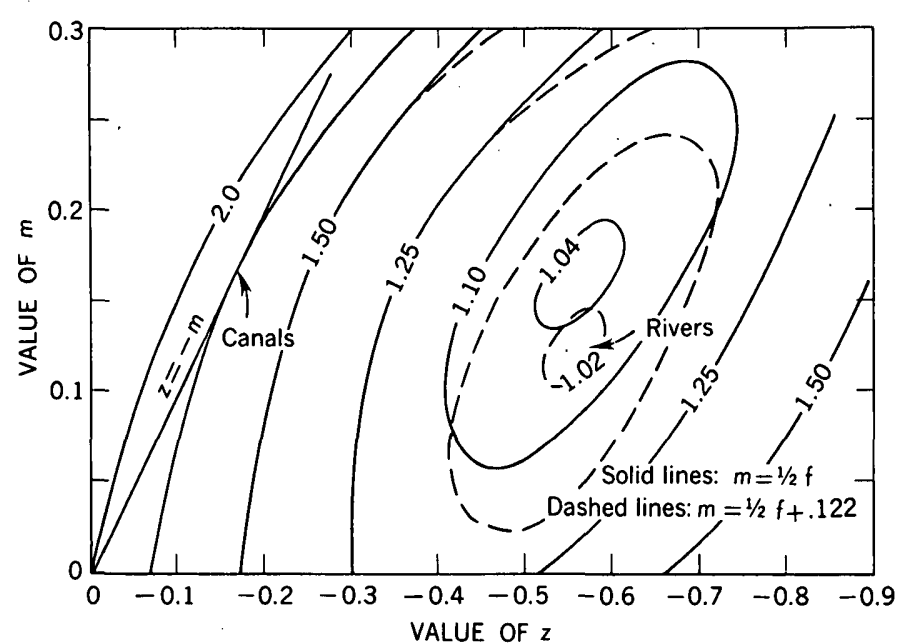

FIGURE 9.-Total of $z^{2}+(m+z)^{2}+(m+f+z)^{2}+(1+z)^{2}+(1+m+z)^{2}$.

$z=-m . \quad$ A line corresponding to this condition is shown on figure 9. This line is tangent to one of the family of curves at a point defined by $m=-z=1 / 6$ and therefore $f=0.33$, and $b=0.50$, as before.

2. There are two minimum sum of squares, without constraint. That minimum defined by the curves for which $m=11_{2}^{\prime} f$ and which occurs at $z=-0.56$ and $m=0.167$ corresponds to the relaxed canal case just dscribed above. The minimum sum of squares defined by the curves for which $m=1 / 2 f+0.12 z$ and which occurs at $z=-0.55$ and $m=0.12$ described the river case.

The agreement between computed and observed hydraulic exponents appears to suggest that the mutual adjustment among them is indeed toward minimum sum of their squares.

One notes that the mutual adjustment among the dependent or adjustable parameters need not be unique but may consist of a set of values distributed about some modal value which can be ascertained from a number of examples as a statistical mode or mean. Average values exist; averages for flume experiments are replicable. Any one example displays equilibrium even when it varies to some degree from this mode or most probable case. The total variance as indicated by the sum of squares of the several examples will be relatively conservative. Wide departures that would contribute greatly to the sum of squares rarely occur, and if they do, they represent temporary conditions in progress toward a more stable form, as indicated by a lower sum of squares of the pertinent hydraulic exponents.

\section{GENERAL STATISTICAL METHODS}

By A. E. Scheidegger

Recently, Leopold and Langbein (1962) postulated empirically an analogy between the statistical evolution of geomorphic features and thermodynamics. Scheidlegger (1964b) then investigated the underlying physical conditions for the validity of this analogy and showed that, indeed, a reasonable microdynamic model could be set up which justified the Leopold-Langbein hypothesis.

A general statistical model of landscape evolution can lead in a broad context to theories of the nonequilibrium and nonstationary state. The basis of this development lies in the idea of considering a particular landscape as a sample of a Gibbsian ensemble. Only statistically valid statements can be deduced for any particular landscape rather than unique solutions. The fact that there is a conservation law of the mass contained in a landscape permits one to introduce a Hamiltonian function and canonical equations, terms that are defined in any textbook on analytical mechanics. The further development of the theory is then automatically the same as in statistical thermodynamics (for this theory see Sommerfeld, 1964).

The general statistical theory in geomorphology of concern here is based upon the concept of conservation of mass. In a one-dimensional section of a landscape (this may be an averaged, representative section) the distribution of heights $h$ can be treated as a statistical function. If we assume that mass transport can occur only within this longitudinal section, then the sum total (that is, the integral) of all the heights taken over the section must be a constant of the motion. In order to have a system with a finite number of degrees of freedom, one may split the length $L$ of the section under consideration into $N$ equal segments. For the $i$ th segrnent, the (mean) height is $h_{i}$. Thus,

$$
H=\sum_{i=1}^{i=N} h_{i}
$$

must be a constant of the motion and can be treated as Hamiltonian. It has been shown (Scheidegger, 1964b) that canonical variables can be introduced by setting

so that

$$
\begin{gathered}
p_{i}=+\sqrt{h_{i}} \\
H=\sum p_{i}^{2}+U\left(q_{i} \ldots q_{N}\right) \\
\dot{q}_{i}=\frac{\partial H}{\partial p_{i}}=2 p_{i} ; \dot{p}_{i}=-\frac{\partial H}{\partial q_{i}}=-\frac{\partial U}{\partial q_{i}} .
\end{gathered}
$$

The function $U$ is the interaction function between the various positions indicated by the index $i$ along the section. 
One can immediately define a partition function at "point" $i$ by

$$
Z=\int_{-\infty}^{+\infty} \int_{-\infty}^{+\infty} e^{-\beta H\left(p_{i} q_{i}\right)} d p_{i} d q_{i}
$$

If the interaction function $U$ is small, this yields

$$
Z=C \frac{\sqrt{\pi}}{\sqrt{\beta}}
$$

with

$$
C \cong \int d q_{i}
$$

Thus, the average height comes out as

$$
\bar{h}=\overline{p^{2}}=\frac{1}{2 \beta} \text {. }
$$

Using the usual thermodynamic functions, we see that the canonical temperature is

$$
T=\frac{1}{k \beta}=\frac{2 \bar{h}}{k}=\bar{h}
$$

if we set $k=2$. There is, therefore, a complete analogy between temperature and average height.

An equilibrium theory sketched above, which is discussed in detail by Scheidegger (1964a), justifies certain analogies that already have been made in geomorphology. However, of greatest interest are its extension to nonequilibrium processes.

A general way by which the theory can be extended to nonequilibrium processes has been indicated by the present author (Scheidegger, 1961b) in a different context. For all practical purposes, this can be accomplished by using Onsager's relations (DeGroot, 1951) and making the assumption that the fluctuations from equilibrium regress linearly. The generalization has been carried out, for example, by DeGroot (1951, p. $41 \mathrm{ff}$.) for the conduction of heat in solids; the theory for the time dependence of the temperature distribution in solids using the canonicity of the variables introduced earlier can be taken over as valid in general for any constant of the motion of a large system that is made up of positive definite contributions from component systems. One thus has, quite generally, as shown earlier (Scheidegger, 1961b), the following theorem: Whenever a system is a linear combination of a large number of fluctuating component systems, and in the "large" systems a certain quantity is a constant of the motion to which the component systems contribute positive definite amounts, then, under equilibrium conditions, that quantity is canonically distributed in the component systems, and under nonequilibrium conditions, assuming linear regression of the fluctuations and microscopic reversibility, the quantity in question is subject to a diffusivity equation with a symmetric diffusivity tensor.

The application of this theorem to the heights in a landscape immediately yields

$$
\frac{\partial \bar{h}\left(x_{i}\right)}{\partial t}=\frac{\partial}{\partial x_{i}} D_{t j} \frac{\partial \bar{h}}{\partial x_{j}}
$$

with $i=1,2$ (referring for example to $x_{i}=$ "north" coordinate and $x_{2}=$ "east" coordinate, respectively), $\bar{h}=$ the (statistical) height, $t=$ time, and $D_{i j}=$ diffusivity tensor; furthermore, the summation convention has been used.

Two exemplary applications of the above diffusivity equation will be investigated. A very well known solution of the diffusivity equation in two dimensions $(\bar{h}, x)$ is given by a Gaussian curve

$$
\bar{h}=\frac{1}{\sqrt{4 \pi D t}} e^{-x^{2} /(\Delta D t)}
$$

This can, for example, be regarded as the time dependence of the decay of an (average) profile of a mountain range. As time proceeds, the mountain range gradually flattens out. The phenomenon is shown in figure 10 .

Another well-known solution of the diffusivity equation in two dimensions $(\bar{h}, x)$ is

$$
h=\frac{1}{2}-\frac{1}{2} \operatorname{erf}\left[x(4 D t)^{-1 / 2}\right]
$$

where erf is again the error function.

This solution can be regarded as representing the decay of the (average) profile of a slope bank. It is the

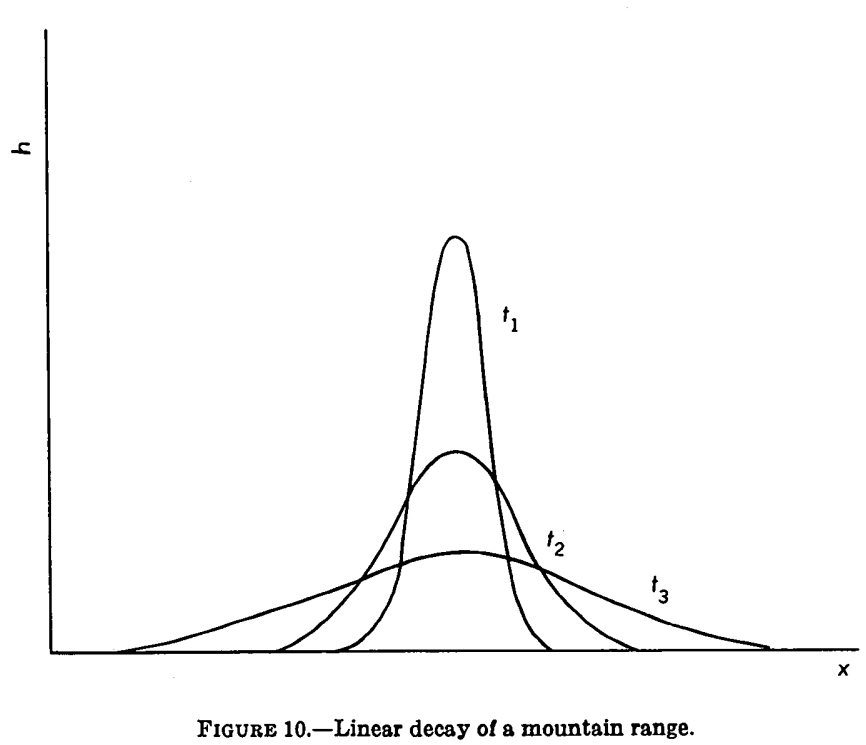


same as that obtained in the random-walk theory without autocorrelation (fig. 3).

The theory given above is completely analogous to the theory of transport processes with mass conservation. The latter encompass such processes as sediment transport in rivers, the spread of a contaminant in a porous medium, and the turbulent mixing of poisonous gáses (see Scheidegger and Chaudhari, 1964). In transport processes with mass conservation, the Hamiltonian refers to a quantity that is conserved in the "large" system.

All the above cases, in turn, are analogous to conditions where the Hamiltonian refers to the energy, that is, to what is commonly called thermodynamics. The discussion of the last paper referred to (Scheidegger and Chaudhari, 1964) is directly applicable to the geomorphic problem. Thus, the interaction between the points of a landscape can be taken into account by defining a suitable interaction function in the Hamiltonian. In the Liouville representation of statistical mechanics (see Prigogine, 1962), the equation describing the evolution of the probability distribution function for the geomorphic heights becomes then very similar to a quantum-dynamic Schrödinger equation. (See, for example, Sommerfeld, 1964.) Similar approximation procedures, as are well known in quantum theory, can therefore be applied.

The proper choice of the interaction function between the various points on a map is not yet clear. If the analogy between landscape evolution and temperature conduction is exploited, various types of diffusivity equations are arrived at for the geomorphic problem. These equations can describe the statistical evolution of a landscape.

\section{SUMMARY}

\section{By W. B. Langbein}

There is today a considerable growth in geomorphology toward a common set of ideas implicit in Chorley's "General Systems" theory, Hack's "Dynamic Equilibrium," or in the statistical concepts described in this paper. In each theory the landscape is viewed in terms less rigid than in the Davisian geographic cycle, with its considerable emphasis upon stage or history.

Dominant, perhaps, is the idea of the landscape as an open system maintained by a continuous (though not constant) supply and removal of material. The steady state exists when there is an average equality between supply and removal. This equation of material is accomplished by means through adjustment of the geometry of the system itself (Chorley, 1962, p. 3). The steady state is believed to correspond with Hack's dynamic equilibrium. It is, however, time independent; that is, different initial conditions may yield similar results (Chorley, p. 8).

Because the steady state is rarely 'characterized by exact equilibrium, the landscape itself manifests a tendency toward a mean condition of forms, recognizable statistically, about which variations may occur (Chorley, 1962, p. 7).

These views that the open-system steady state of the landscape can be described statistically have led us to an attempt to introduce consistent methods of giving these concepts quantitative expression. The theories of diffusion processes, random walks, and Markov processes provide some of the techniques. Minimum variance theory offers a method for estimating the variation in the geometry of rivers and possibly of other features of the terrain.

The present analysis, instead of one specific landscape or river, treats of a whole ensemble of landscapes or rivers which are "macroscopically identical" in the face of one's ignorance about their details. Because of one's ignorance, only averages can be derived.

It is further assumed that each particle $(=\mathrm{a}$ small volume of solid or a volume of fluid small enough not to be separated in its journeys) will, under steady-state conditions, in time meet all the conditions that are present in the many landscapes or rivers composing the ensemble. In other words, time averages and ensemble averages can be exchanged. This is called the ergodic hypothesis.

If, for example, the ensemble consists of rivers having a prescribed rate of change of discharges, then only average rates of changes of the associated river properties can be dervied, although inferences may also be derived about the variance among the individuals composing the ensemble. It is assumed that the ensemble of all rivers having the given rate of change of discharge at any time contains samples of the changes that will occur in any given river over time.

\section{REFERENCES}

Ackers, Peter, 1964, Experiments on small streams in alluvium Am. Soc. Civil Engineers, Jour. Hydraulies Div., v. 90, No. HY4, Proc. Paper 3959 p. 1-37.

American Geological Institute, 1957, Glossary of geology and related sciences: Am. Geol. Inst., 325 p.

Bakhemeteff, B. A., 1941, The mechanics of turbulent flow: Princeton, N. J., Princeton Univ. Press, 101 p.

Bakker, J. P., and Strahler, A. N., 1956, Report on quantitative treatment of slope recession problems: Internat. Geog. Union, 18th, Rio de Janeiro 1956, 1er Rap. Comm. étude des versants, p. 30-41.

Bharucha-Reid, A. T., 1960, Elements of the theory of Markov processes and their applications: New York, McGraw-Hill Book Co., 468 p.

Brune, G. M., 1948, Rates of sediment movement in midwestern United States: U.S. Soil Conserv. Service SCS-TP-65, 40 p. 
Chorley, R. J., 1962, Geomorphology and general systems theory: U.S. Geol. Survey Prof. Paper 500-B, 10 p.

Culling, W. E. H., 1963, Soil creep and the development of hillside slopes: Jour. Geol. v. 71, p. 127-161.

Davis, R. M., 1924, Die erklärende Beschreibung der Landformen: Berlin, Teubner, 565 p.

DeGroot, S. R., 1951, Thermodynamics of irreversible processes: Amsterdam, North Holland Publishing Co., 242 p.

Fahnestock, R. K., 1963, Morphology and hydrology of a glacial stream-White River, Mount Rainier, Washington: U.S. Geol. Survey Prof. Paper 422-A, 70 p. [1964].

Goldstein, S., 1951, On diffusion by discontinuous movements and on the telegraph equation: Quart. Jour. Mech. Appl. Math. v. 4, p. 129-156.

Hack, J. T., 1960, Interpretation of erosional topography in humid temperate regions: Am. Jour. Sci., v. 258-A, p. 80-97.

Jeffreys, Harold, 1932, Cartesian tensors 1931: London Cambridge Univ. Press, 92 p. [Repr., 1962].

Lacey, Gerald, 1930, Stable channels in alluvium: Inst. Civil Engineers Proc., v. 229; pt. 1, p. 259-384.

Leopold, L. B., and Langbein, W. B., 1962, The concept of entropy in landscape evolution: U.S. Geol. Survey Prof. Paper 500-A, 20 p.

Leopold, L. B., and Maddock, Thomas, Jr., 1953, The hydraulic geometry of stream channels and some physiographic implications: U.S. Geol. Survey Prof. Paper 252, 57 p.

Lotka, A. J., 1925, Elements of physical biology: Baltimore, Williams \& Wilkins Co., 460 p.

Matalas, N. C., and Conover, W. J., 1964, Derivation of the velocity profile from a statistical model of turbulence: Water Resources Research, v. 1, No. 2, p. 235-261 [i965].

Melton, M. A., 1958, Correlation structure of morphometric properties of drainage systems and their controlling agents: Jour. Geol., v. 66, No. 4, p. 442-460.

Mises, R. V., 1931, Wahrscheinlichkeitsrechung: Leipzig, Germany, Deuticke, 574 p.

Nizery, A., and Braudeau, G., 1955, Discussion of "Design of stable channels," by E. W. Lane: Am. Soc. Civil Engineers Trans., v. 120, p. 1268.
Prigogine, I., 1962, Nonequilibrium statistical mechanics: New York, John Wiley \& Sons, 319 p.

Rubey, W. W., 1938, The force required to move particles on a stream bed: U.S. Geol. Survey Prof. Paper 189-E, p. 138.

Scheidegger, A. E., 1958, The random-walk model with autocorrelation of flow through porous media: Canadian Jour. Physics, v. 36, p. 649-658.

- 1961a, Mathematical models of slope development: Geol. Soc. America Bull., v. 72, p. 37-50.

$1961 \mathrm{~b}$, On the statistical properties of some transport equations: Canadian Jour. Physics, v. 39, p. 1573-1582.

- 1964a, Statistical hydrodynamics in porous media: Advances in Hydroscience, v. 1, p. 161-181.

$1964 \mathrm{~b}$, Some implications of statistical mechanics in geomorphology: Internat. Assoc. Sci. Hydrology Bull., v. 9, no. 1, p. 12-16.

1964c, Lithologic variations in slope development theory: U.S. Geol. Survey Circ. 485, 8 p.

Scheidegger, A. E., and Chaudhari, N. M., 1964, Some statistical properties of certain geophysical transport equations: Pure and Appl. Geophysics, v. 49, p. 1-12.

Schenk, Hilbert, 1963, Simulation of the evolution of drainagebasin networks with a digital computer: Jour. Geophys. Research, v. 68, p. 5739-5745.

Simons, D. B., Richardson, E. V., and Albertson, M. L., 1961, Flume studies using medium sand $(0.45 \mathrm{~mm})$ : U.S. Geol. Survey Water-Supply Paper 1498-A, 76 p.

Sommerfeld, A., 1964, Thermodynamics and statistical mechanics, v. 5 of Lectures on theoretical physics: New York, Academic Press, $401 \mathrm{p}$.

Souchez, R., 1963, Evolution des versants et théorie de la plasticité: Rev. belge Géographie, v. 87, No. 1, p. 7-94.

Southwell, R. V., 1940, Relaxation methods in engineering science: London, Oxford Univ. Press, 252 p.

Wolman, M. G., and Brush, L. M., 1961, Factors controlling size and shape of stream channels in coarse noncohesive sands: U.S. Geol. Survey Prof. Paper 282-G, 210 p.

Wolman, M. G., and Miller, J. P., 1960, Magnitude and frequency of forces in geomorphic processes: Jour. Geol., v. 68, p. 54-74. 